\title{
Exogenous glutamate rapidly induces the expression of genes involved in metabolism and defense responses in rice roots
}

\author{
Chia-Cheng Kan ${ }^{\dagger}$, Tsui-Yun Chung ${ }^{\dagger}$, Hsin-Yu Wu, Yan-An Juo and Ming-Hsiun Hsieh ${ }^{*}$ (D)
}

\begin{abstract}
Background: Glutamate is an active amino acid. In addition to protein synthesis and metabolism, increasing evidence indicates that glutamate may also function as a signaling molecule in plants. Still, little is known about the nutritional role of glutamate and genes that are directly regulated by glutamate in rice.

Results: Exogenous glutamate could serve as a nitrogen nutrient to support the growth of rice seedlings, but it was not as effective as ammonium nitrate or glutamine. In nitrogen-starved rice seedlings, glutamate was the most abundant free amino acid and feeding of glutamate rapidly and significantly increased the endogenous levels of glutamine, but not glutamate. These results indicated that glutamate was quickly metabolized and converted to the other nitrogen-containing compounds in rice. Transcriptome analysis revealed that at least 122 genes involved in metabolism, transport, signal transduction, and stress responses in the roots were rapidly induced by $2.5 \mathrm{mM}$ glutamate within $30 \mathrm{~min}$. Many of these genes were also up-regulated by glutamine and ammonium nitrate. Still, we were able to identify some transcription factor, kinase/phosphatase, and elicitor-responsive genes that were specifically or preferentially induced by glutamate.

Conclusions: Glutamate is a functional amino acid that plays important roles in plant nutrition, metabolism, and signal transduction. The rapid and specific induction of transcription factor, kinase/phosphatase and elicitor-responsive genes suggests that glutamate may efficiently amplify its signal and interact with other signaling pathways to regulate metabolism, growth and defense responses in rice.
\end{abstract}

Keywords: Rice, Glutamate, Metabolism, Signal transduction, Gene expression, Transcription factor, Defense response

\section{Background}

Glutamate and glutamine are the first organic nitrogen compounds derived from the assimilation of nitrate and ammonium in plants. In the primary nitrogen assimilation pathway, nitrate taken up from the soil is reduced to nitrite and ammonium by nitrate and nitrite reductase, respectively. Ammonium derived from nitrate or directly absorbed from the soil can be assimilated into glutamine and glutamate via the glutamine synthetase (GS)/glutamineoxoglutarate aminotransferase (GOGAT) cycle [1-3]. In addition to the primary nitrogen assimilation pathway,

* Correspondence: ming@gate.sinica.edu.tw

${ }^{\dagger}$ Equal contributors

Institute of Plant and Microbial Biology, Academia Sinica, Taipei, Taiwan glutamate and glutamine can be synthesized via the remobilization of nitrogen-containing compounds and the assimilation of large amounts of ammonium generated by photorespiration in C3 plants [4]. Thus, glutamate and glutamine are closely related in metabolism. Besides glutamine, glutamate can be derived from other amino acids of the glutamate family such as arginine, ornithine, and proline in the plant cell [5].

In addition to protein synthesis, glutamate has many important functions in plants. For instance, glutamate is a major amino donor for the synthesis of amino acids and other nitrogen-containing compounds in plants [5]. The $\alpha$-amino group of glutamate can be transferred to a wide variety of $\alpha$-keto acids to form amino acids, which 
are catalyzed by reversible pyridoxal-5' - phosphatedependent aminotransferases. In addition to transamination reactions, glutamate can be directly converted to $\alpha$ ketoglutarate, which is mainly catalyzed by glutamate dehydrogenase (GDH) in plants [5]. The active conversion between glutamate and $\alpha$-ketoglutarate provides a direct link between nitrogen and carbon metabolism in the cell.

In addition to primary carbon and nitrogen metabolism, glutamate is required for the synthesis of glutathione (GSH), a linear tripeptide of glutamate, cysteine, and glycine and a major intracellular antioxidant in virtually all organisms [6]. Glutamate is also a precursor for the synthesis of photosynthetic pigment chlorophyll. In addition, glutamate can be converted to $\gamma$-aminobutyrate (GABA) via glutamate decarboxylase (GDC). GABA is a non-protein amino acid that rapidly accumulates in response to biotic and abiotic stress to modulate plant growth [7-9]. Increasing evidence indicates that GABA may exert its effects in plants through the regulation of carbon metabolism as well as signaling pathways [7-11]. Glutamate also plays an important role in the synthesis of functional folate (vitamin B9), which is a cofactor for one-carbon metabolism. Folate is predominantly decorated with a polyglutamate tail. The addition of polyglutamate to folate may enhance its co-enzyme affinity, subcellular compartmentation and stability [12].

In humans, glutamate and its metabolite GABA are important neurotransmitters in the central nervous system. Glutamate mainly employs its action through glutamate receptors [13], which also exist in non-neuronal tissues [14-16]. Thus, the functions of glutamate signaling may go beyond the nervous system [14-16]. Interestingly, plants also have glutamate receptor (GLR) homologs [17]. There are 20 GLR genes grouped into three clades in the model plant Arabidopsis thaliana [18]. The functions of these GLRs have just begun to be elucidated. Accumulating evidences suggest that plant GLRs may not have ligand specificity [19]. For instance, AtGLR1.4 is an ion channel gated by multiple hydrophobic amino acids but not glutamate [20]. Thus, GLRs may have evolved to have diverse functions in plants. Nevertheless, the discovery of GLR homologs has laid the foundation for the assessment of glutamate sensing and signaling in plants.

Glutamate has been implicated to modulate calcium signaling [21] and root system architecture [22, 23]. Glutamate inhibits primary root growth and stimulates the outgrowth of lateral roots near the primary root tip in Arabidopsis [22]. This phenomenon is specific to glutamate, as structurally or metabolically related amino acids Asp, Gln, and D-Glu do not have similar effects [22]. A recent study further demonstrated that a MAP kinase kinase kinase (MEKK1) is involved in glutamate signaling pathway responsible for inducing changes in Arabidopsis root system architecture [24]. The MAP kinase cascade plays an important role in both biotic and abiotic stress signaling networks [25]. The identification of MEKK1 in glutamate signaling raises an interesting question whether amino acid signaling interacts with biotic and abiotic stress signaling in plants. Recently, exogenous glutamate $(10 \mathrm{mM})$ has been shown to induce systemic disease resistance in rice but the underlying molecular mechanisms are still unknown [26].

While glutamate has been shown to serve as an external signal to affect root growth and development in the most sensitive Arabidopsis accession C24 at a very low concentration $(50 \mu \mathrm{M})$ [22], most studies on the effects of glutamate on the growth of seedlings or suspension cultures use 1-10 $\mathrm{mM}$ or even higher concentrations of glutamate [19]. It has been demonstrated that feeding of 20 or $40 \mathrm{mM}$ glutamate to tobacco plants has limited effect on the endogenous glutamate pool [27, 28]. Feeding of $100 \mathrm{mM}$ glutamate induces the expression of glutamate metabolic genes cytosolic glutamine synthetase (GS1) and glutamate dehydrogenase $(G D H)$ in tobacco leaf discs [29]. Together with studies on glutamate metabolism related enzymes using inhibitors, mutants, overexpression and antisense lines, it has been proposed that plants may have mechanisms to maintain glutamate homeostasis [5]. GS and GDH may be responsible for maintaining a constant concentration of glutamate in plants [30].

Amino acids have been shown to act as signals to regulate gene expression in yeast and animals [31, 32]. It is somewhat surprising that relatively few studies have focused on the effects of exogenous amino acids on plant gene expression [19]. We have previously shown that glutamine can effectively support rice seedling growth when supplemented as the sole nitrogen source in hydroponics [33]. In addition to its role in plant nutrition, glutamine can rapidly induce the expression of key transcription factor genes involved in nitrogen and stress responses in rice roots [33, 34]. These findings support the notion that amino acid signaling pathways may crosstalk with biotic and abiotic signaling networks in plants. Although glutamate and glutamine are closely related in structure and metabolism, these two amino acids may have distinct signaling effects. Here, we examined the nutritional effects of glutamate on rice seedlings. We also used transcriptome analysis to identify genes that were rapidly induced by glutamate in rice roots. Some of the early glutamateresponsive genes identified here may be involved in glutamate signaling in plants.

\section{Results}

Exogenous glutamate can support rice seedling growth

Glutamate occupies a central position in plant metabolism and serves as a precursor for many important compounds (Additional file 1: Figure S1). To examine the nutritional effect of glutamate, we grew rice seedlings in hydroponics 
supplemented with different concentrations of glutamate as the sole nitrogen source (Fig. 1). Feeding of $0.1 \mathrm{mM}$ glutamate did not significantly (one-way ANOVA followed by Tukey's test, $P<0.05)$ improve the growth of rice seedlings (Fig. 1a,b), and the chlorophyll content only increased slightly (Fig. 1c) as compared with those of seedlings grown in the absence of nitrogen. The shoot length of rice seedlings grown in 0.5 and $1 \mathrm{mM}$ glutamate was significantly longer than that grown in the absence of nitrogen, but was

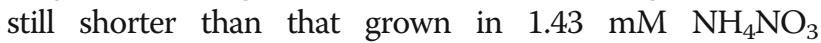
(Fig. 1a,b). Supplementation of 2.5, 5, or $10 \mathrm{mM}$ glutamate in the hydroponics inhibited shoot growth as compared with that of 0.5 or $1 \mathrm{mM}$ glutamate (Fig. 1a,b). The root length of rice seedlings grown in $0.1 \mathrm{mM}$ glutamate was similar to that of seedlings grown in the absence of nitrogen (Fig. 1a,b). Feeding of 0.5, 1, 2.5, 5, or $10 \mathrm{mM}$ glutamate in the hydroponics increasingly inhibited root growth as compared with that of $1.43 \mathrm{mM} \mathrm{NH}_{4} \mathrm{NO}_{3}$ (Fig. 1a,b). Although glutamate was not as effective as ammonium nitrate in supporting rice seedling growth, the chlorophyll content in seedlings grown in $0.5-10 \mathrm{mM}$ glutamate was comparable to that of seedlings grown in $1.43 \mathrm{mM} \mathrm{NH}_{4} \mathrm{NO}_{3}$ (Fig. 1c).

\section{Slow uptake of glutamate in nitrogen-starved rice seedlings}

To examine if rice seedlings could effectively take up glutamate, 17-day-old nitrogen-starved rice seedlings were transferred to hydroponics containing $2.5 \mathrm{mM}$ glutamate for $0-24 \mathrm{~h}$. The content of glutamate left in the growth medium was measured during the time course of glutamate feeding. The amount of glutamate left in the growth medium only decreased slightly after $0.25-8 \mathrm{~h}$ of treatment (Fig. 2a). Approximately $20 \%$ and $50 \%$ of the glutamate supplemented in the hydroponics were consumed after $16 \mathrm{~h}$ and $24 \mathrm{~h}$ of treatment, respectively (Fig. 2a).

\section{Glutamate is rapidly converted to other amino acids in the roots}

After taken up by the nitrogen-starved rice seedlings, glutamate may be converted to other nitrogen-containing compounds. We analyzed the levels of free amino acids in the roots during the time course of glutamate treatment. The levels of glutamate, aspartate, serine, glutamine, asparagine, and alanine increased significantly (one-way ANOVA followed by Tukey's test, $P<0.05$ ) after $24 \mathrm{~h}$ of glutamate treatment as compared to the untreated control (Fig. 2b, Additional file 1: Table S1). By contrast, the amounts of the other proteinogenic amino acids did not change significantly (data not shown). Interestingly, feeding of glutamate to nitrogen-starved rice seedlings did not significantly increase the endogenous levels of glutamate within $30 \mathrm{~min}$ (Fig. 2b). Glutamate in the roots started to accumulate to a higher level after feeding for $1 \mathrm{~h}$ and
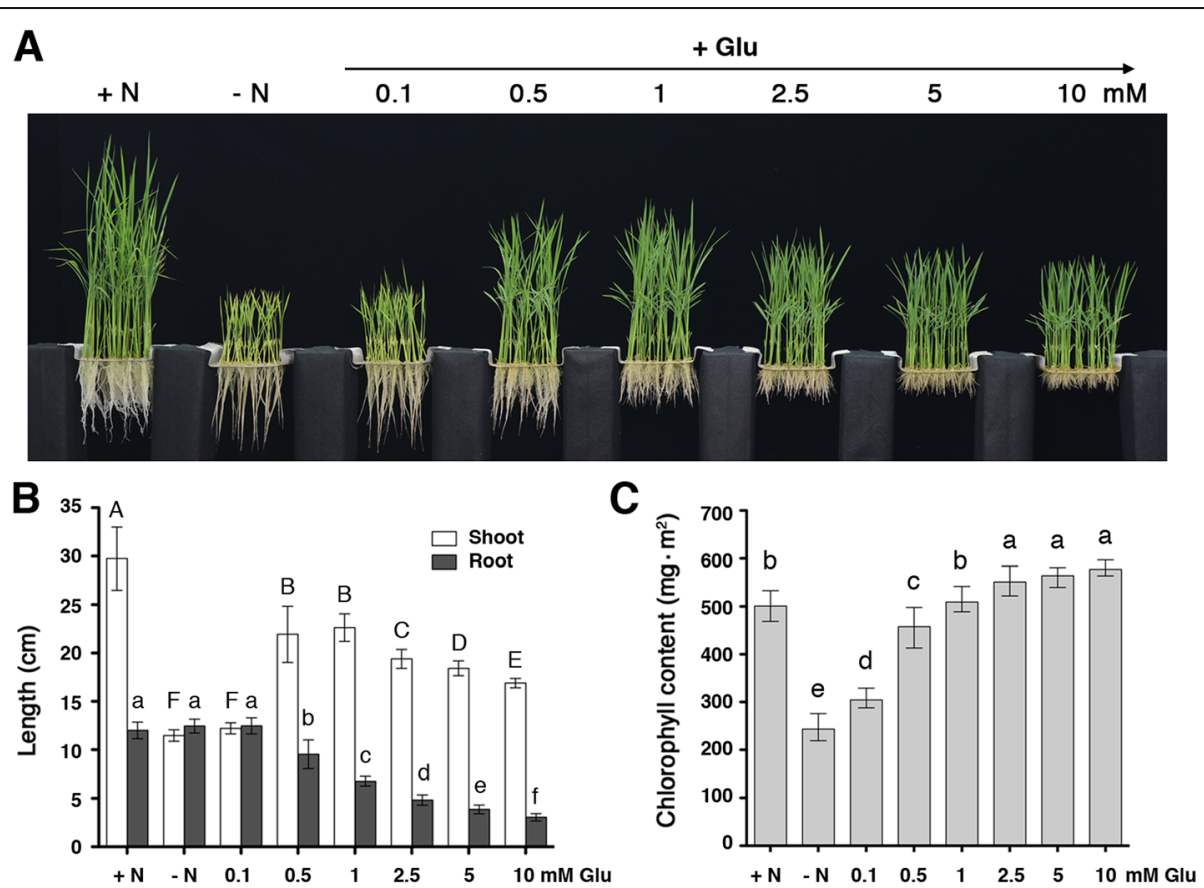

Fig. 1 Glutamate as a nitrogen nutrient to support rice seedling growth. a Rice seedlings grown in hydroponics containing $\mathrm{NH}_{4} \mathrm{NO}_{3}$ or glutamate as the nitrogen source. Shoot length, root length (b), and chlorophyll contents (c) of rice seedlings from (a). The rice seedlings are 17-day-old. Data are means \pm SD $(n=40)$. Different letters indicate significant differences between treatments, tested by one-way ANOVA followed by Tukey's test $(P<0.05) .+\mathrm{N},+1.43 \mathrm{mM} \mathrm{NH}_{4} \mathrm{NO}_{3} ;-\mathrm{N}$, no nitrogen 

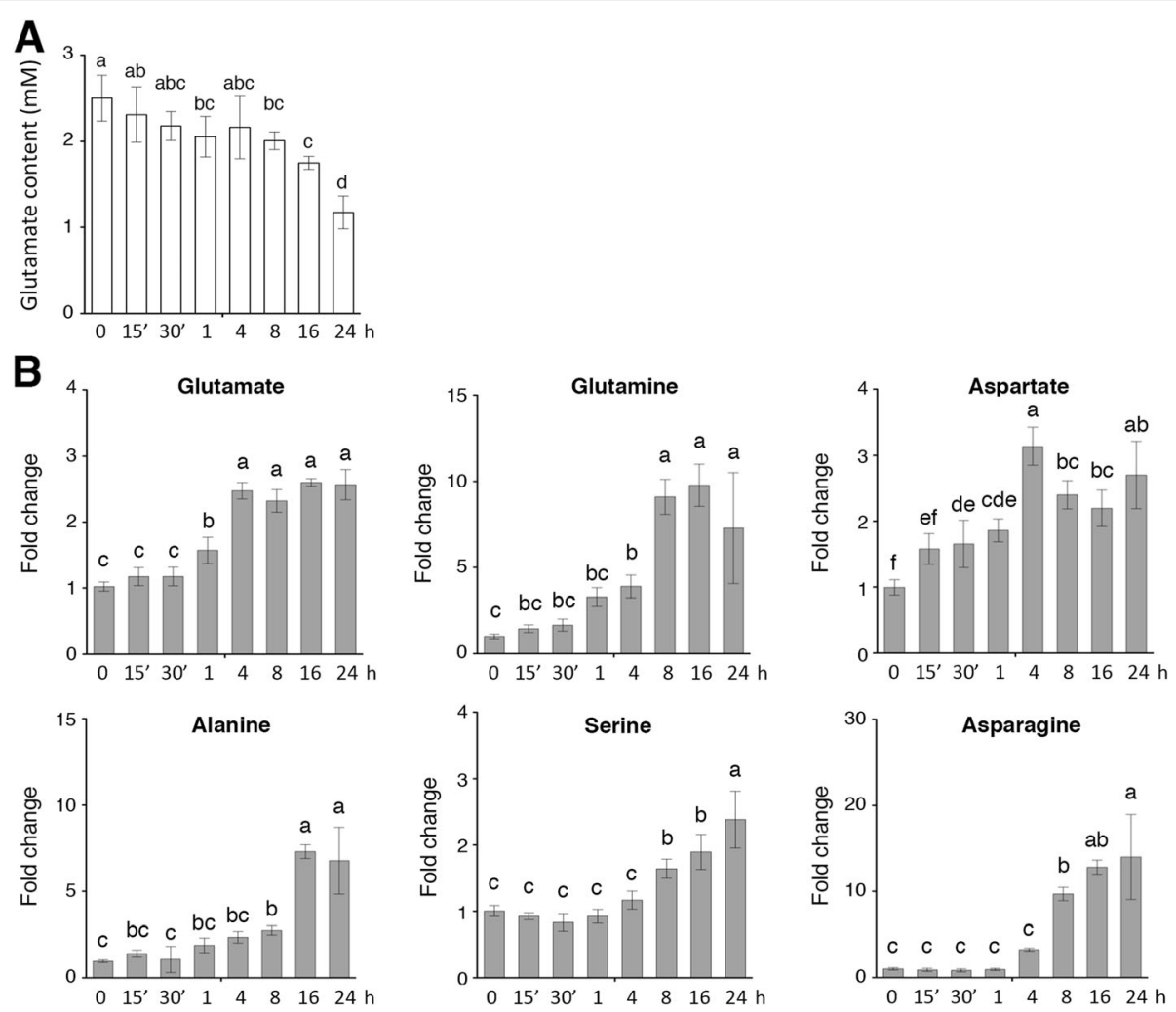

Fig. 2 Amino acid contents in the growth medium and rice roots during the time course of glutamate treatment. 17-day-old nitrogen-starved rice seedlings were transferred to hydroponics containing $2.5 \mathrm{mM}$ glutamate for $24 \mathrm{~h}$. a The contents of glutamate left in the hydroponics were measured over the 24-h time course. $\mathbf{b}$ Contents of glutamate, glutamine, aspartate, alanine, serine, and asparagine in the roots were measured during the time course of glutamate treatment. Fold change indicates the relative amounts of amino acids in $2.5 \mathrm{mM}$ glutamate-treated roots $(0.25-24 \mathrm{~h})$ compared to those of control $(0 \mathrm{~h})$. Data are means \pm SD $(n=5)$. Different letters indicate significant differences between treatments, tested by one-way ANOVA followed by Tukey's test $(P<0.05)$

increased to about 2.5-fold of control levels after $4 \mathrm{~h}$ of glutamate treatment (Fig. 2b). Although the exogenous amount of glutamate in the growth medium decreased significantly after 8-24 h (Fig. 2a), the endogenous levels of glutamate in the roots did not further increase after $8-24 \mathrm{~h}$ of glutamate treatment (Fig. 2b). These results suggest that the glutamate taken up by the rice seedlings may be constantly converted to the other nitrogen-containing compounds in the roots.

The amount of glutamine, aspartate and alanine increased rapidly after $15 \mathrm{~min}$ of glutamate treatment (Fig. 2b). Feeding of glutamate to nitrogen-starved rice seedlings significantly increased the endogenous levels of glutamine after 15-30 min (Fig. 2b). The amount of glutamine in the roots increased to about 3 -fold after $1 \mathrm{~h}, \sim 5$-fold after $4 \mathrm{~h}$, and continued to increase to $\sim 10$-fold of control levels after $8-24$ h of glutamate treatment (Fig. 2b). Similar trend was observed in changes of alanine levels during the time course of glutamate treatment. The amount of alanine increased to about 2.5- to 3-fold after 4-8 h, and continued to increase to $\sim 8$-fold of control levels after 16-24 h of glutamate treatment (Fig. 2b). Feeding of glutamate to nitrogenstarved rice seedlings rapidly enhanced the accumulation of aspartate within the first hour, and the levels of aspartate increased to about 2- to 3.3-fold of control levels after 4-24 h of glutamate treatment (Fig. 2b).

By contrast, feeding of glutamate to nitrogen-starved rice seedlings did not significantly increase the amount of serine in the roots within the first $4 \mathrm{~h}$ (Fig. 2b). The levels of serine increased to about 2- to 3-fold of control levels after 8-24 h of glutamate treatment (Fig. 2b). The amount of asparagine was low in nitrogen-starved seedlings, and feeding of glutamate for $0.25-4 \mathrm{~h}$ did not significantly increase the levels of asparagine in the roots (Fig. 2b). The amount of asparagine started to increase significantly ( $\sim 12$-fold) after $8 \mathrm{~h}$ of glutamate treatment, and continued to increase to $\sim 16$-fold after $16 \mathrm{~h}$, and $\sim 20$-fold of control levels after $24 \mathrm{~h}$ (Fig. 2b).

\section{Identification of early glutamate-responsive genes in rice seedlings}

In addition to nutritional effects, we attempted to explore the signaling role of glutamate in the regulation of 
gene expression in rice. To identify genes that were rapidly induced by glutamate, we used microarray analysis to compare the gene expression profiles between rice seedlings treated with $2.5 \mathrm{mM}$ glutamate for $30 \mathrm{~min}$ and the untreated control. Analysis of the microarray data with 2-fold cutoff revealed that the expression of 156 genes was rapidly regulated by glutamate in the roots. Of the 156 genes, including 151 up- and 5 downregulated, we were able to confirm the up-regulation of 122 genes (Table 1), and none of the down-regulated genes could be verified by qRT-PCR (see below). In contrast to roots, the microarray data did not identify any genes that were rapidly induced by glutamate in the shoots (2-fold cutoff, data not shown). This is consistent with the finding that levels of free amino acids did not change significantly (Student's $t$-test, $P<0.05$ ) in the shoots after $30 \mathrm{~min}$ of glutamate treatment (Additional file 1: Figure S2A). Unexpectedly, the treatment also did not significantly increase the levels of glutamate in the roots, while the amounts of glutamine, aspartate, and alanine increased slightly (Additional file 1: Figure S2B).

We used gene ontology (GO) category enrichment analysis to classify the biological functions of 122 genes up-regulated by glutamate in rice roots. In biological process, the GO terms "metal ion transport", "protein amino acid phosphorylation", and "amine metabolic process" were significantly (false discovery rate value, FDR $<0.05)$ enriched (Fig. 3a). In cellular component, the GO term "membrane" was enriched (Fig. 3b). In molecular function, the GO terms "hydrolase activity", "protein kinase activity", "active transmembrane transporter activity", "cation transmembrane transporter activity", "ATP binding" and "calcium ion binding" were significantly enriched (Fig. 3c). Some of the glutamate up-regulated genes in representative functional categories were listed in Additional file 1: Table S2.

In addition, we also performed Kyoto encyclopedia of genes and genomes (KEGG) analysis. Of the 122 upregulated genes, 33 genes were annotated with KEGG orthology $(\mathrm{KO})$ terms. A list of these genes, the associated KO number and KEGG pathways were shown in Additional file 1: Table S3. We further performed KEGG pathway enrichment analysis and the result indicated that "glycerophospholipid metabolism" and "ABC transporters" were enriched (Additional file 1: Table S4). Since the gene count was very low, 2 in "glycerophospholipid metabolism" and only 1 in "ABC transporters", the result of KEGG pathway enrichment analysis might not be meaningful. Nevertheless, the results of GO and KEGG analyses suggest that glutamate feeding for $30 \mathrm{~min}$ can rapidly trigger the expression of genes involved in metabolism, transport and signaling in rice roots.

The functions of the early glutamate-responsive genes are very diverse. Of the 122 genes identified, at least 11 genes encode putative transcription factors. The Os07g0589000 gene encodes a homolog of Arabidopsis LBD37 that is involved in the regulation of nitrogen response [35]. CIGR2 (Os07g0583600), an elicitor-responsive gene, encodes a GRAS family protein that has been shown to suppress cell death in rice [36]. NAC5 (Os11g0184900), no apical meristem protein 5 , is involved in abiotic stress responses [37-39]. The expression of Os04g0301500 (basic helixloop-helix $35, b H L H 35$ ) is rapidly induced by jasmonate, and thus has been named RERJ1 [40-42]. The other glutamate-responsive transcription factor genes include Os09g0401000 (MYB family protein), Os01g0705700 (bHLH13), Os02g0764700 (ERF109), Os11g0154500 (NAC90), Os09g0455300 (bHLH, similar to HECATE1), Os07g0119300 (MYB family protein), and Os08g0386200 (WRKY69).

The expression of Os03g0236200 (glutamate decarboxylase 1, GDC1) and Os04g0543900 (glutamate dehydrogenase 2, GDH2) was rapidly induced by glutamate (Table 1 ). The enzymes encoded by these two genes are directly involved in glutamate metabolism. In addition to genes related to metabolism and transport, many genes involved in signal transduction, growth regulation, defense and stress responses were also rapidly induced by glutamate (Table 1 ). For instance, the expression of several genes encoding kinases, phosphatases, and calcium signaling related proteins was rapidly induced by glutamate (Table 1). The cell wall associated kinases (WAKs) may serve as pectin receptors to regulate plant growth and stress responses [43, 44]. Interestingly, glutamate rapidly induced the expression of several WAK genes (Table 1). The indole-3-acetic acidamido synthetase OsGH3.8 functioning in auxin-dependent development can promote salicylate- and jasmonateindependent basal immunity in rice [45]. The expression of OsGH3.8 (Os07g0592600) was rapidly and strongly induced by different concentrations of glutamate (Table 1 , Additional file 1: Figure S3, no. 41). Several defenserelated genes such as herbivore induced 13-lipoxygenase (HI-LOX, Os08g0508800), chitinase 6 (Os02g0605900) and 8 (Os10g0542900) were also rapidly induced by glutamate (Table 1).

\section{Regulation of early glutamate-responsive genes by different concentrations of glutamate}

To verify the microarray data, total RNA extracted from 17-day-old rice seedlings treated with $0-5 \mathrm{mM}$ glutamate for $30 \mathrm{~min}$ was used for qRT-PCR analysis. We were able to confirm that glutamate $(2.5 \mathrm{mM}, 30 \mathrm{~min})$ could induce the expression of 122 genes for more than 2-fold as compared to the untreated control. The effects of different concentrations of glutamate on the expression of these genes are shown in Fig. 4 and Additional file 1: Figure S3. In addition to verifying the microarray data, the results could also reveal the sensitivity and dosage 
Table 1 List of early glutamate-responsive genes in rice roots

\begin{tabular}{|c|c|c|c|c|}
\hline No. & Locus ID & & Fold change (+ Glu/- N) & Gene description \\
\hline $1^{a}$ & Os03g0236200 & LOC_Os03g13300 & 9.6 & Glutamate decarboxylase 1, GDC1 \\
\hline 2 & Os08g0508800 & LOC_Os08g39840 & 5.4 & Herbivore induced 13-lipoxygenase, HI-LOX \\
\hline 3 & Os12g0518200 & LOC_Os12g33300 & 5.1 & EamA-like transporter family \\
\hline 4 & Os04g0618400 & LOC_Os04g52750 & 5.1 & Unknown \\
\hline $5^{\mathrm{a}}$ & Os03g0823400 & LOC_Os03g60840 & 4.7 & Bowman-Birk type trypsin inhibitor, BBTI13 \\
\hline 6 & Os09g0401000 & LOC_Os09g23620 & 4.6 & MYB family transcription factor \\
\hline $7^{\mathrm{a}}$ & Os05g0402900 & LOC_Os05g33400 & 4.3 & Xylanase inhibitor I-like \\
\hline 8 & Os01g0186900 & LOC_Os01g09220 & 4.2 & Putative nuclease HARBI1 \\
\hline 9 & Os08g0457200 & LOC_Os08g35580 & 4.2 & Unknown \\
\hline 10 & Os05g0373300 & LOC_Os05g30970 & 3.9 & Copine-like protein; similar to BONZAI1 \\
\hline 11 & Os01g0952900 & LOC_Os01g72360 & 3.8 & Unknown \\
\hline 12 & Os01g0705200 & LOC_Os01g50910 & 3.7 & Late embryogenesis abundant protein, group 3 \\
\hline 13 & Os12g0181500 & LOC_Os12g08090 & 3.7 & Amino acid permease 16, AAP16 \\
\hline 14 & Os01g0666000 & LOC_Os01g47580 & 3.6 & Lipid phosphate phosphatase 2 \\
\hline 15 & Os03g0318400 & LOC_Os03g20290 & 3.6 & Aspartic proteinase nepenthesin-1 \\
\hline $16^{\mathrm{a}}$ & Os04g0301500 & LOC_Os04g23550 & 3.6 & Transcription factor bHLH35, RERJ1 \\
\hline 17 & Os02g0269600 & LOC_Os02g16940 & 3.6 & Subtilisin-like protease SBT3.5 \\
\hline 18 & Os09g0565300 & LOC_Os09g39190 & 3.5 & E3 ubiquitin-protein ligase RGLG1 \\
\hline 19 & Os10g0542900 & LOC_Os10g39680 & 3.5 & Chitinase 8 \\
\hline 20 & Os02g0605900 & LOC_Os02g39330 & 3.4 & Chitinase 6 \\
\hline 21 & Os09g0551000 & LOC_Os09g37834 & 3.3 & G-type lectin S-receptor-like protein kinase RKS1 \\
\hline $22^{\mathrm{a}}$ & Os01g0845100 & LOC_Os01g62670 & 3.3 & Protein of unknown function DUF668 \\
\hline 23 & Os11g0213800 & LOC_Os11g10770 & 3.2 & NBS-LRR disease resistance protein \\
\hline 24 & Os03g0302800 & LOC_Os03g19070 & 3.2 & Unknown \\
\hline $25^{\mathrm{a}}$ & Os02g0687200 & LOC_Os02g46210 & 3.1 & Protein of unknown function DUF581 \\
\hline 26 & Os01g0905300 & LOC_Os01g67820 & 3.1 & Exo70 exocyst complex subunit \\
\hline 27 & Os10g0497700 & LOC_Os10g35460 & 3.1 & COBRA-like protein 4 \\
\hline 28 & Os02g0733900 & LOC_Os02g50110 & 3.1 & Unknown \\
\hline 29 & Os04g0585000 & LOC_Os04g49550 & 3.0 & RING-H2 finger protein ATL44 \\
\hline 30 & Os05g0516700 & LOC_Os05g44060 & 3.0 & Unknown \\
\hline $31^{a}$ & Os03g0187800 & LOC_Os03g08880 & 3.0 & Purine permease 3 , PUP3 \\
\hline 32 & Os04g0647900 & LOC_Os04g55420 & 3.0 & LRR receptor-like serine/threonine protein kinase GSO1 \\
\hline 33 & Os01g0705700 & & 2.9 & Transcription factor bHLH13 \\
\hline 34 & Os10g0418100 & LOC_Os10g28240 & 2.9 & Calcium-transporting ATPase 13 \\
\hline 35 & Os07g0559700 & LOC_Os07g37320 & 2.9 & Monosaccharide transporter 6, OsMST6 \\
\hline 36 & Os11g0144900 & LOC_Os11g04830 & 2.9 & Unknown \\
\hline 37 & Os04g0464100 & LOC_Os04g39010 & 2.8 & Heavy metal transport domain-containing protein \\
\hline 38 & Os09g0471800 & LOC_Os09g29600 & 2.8 & Wall-associated receptor kinase 85, OsWAK85 \\
\hline 39 & Os12g0478400 & LOC_Os12g29430 & 2.8 & Wall-associated receptor kinase 125, OsWAK125 \\
\hline 40 & Os04g0128700 & LOC_Os04g03920 & 2.8 & Unknown \\
\hline 41 & Os07g0592600 & LOC_Os07g40290 & 2.8 & Indole-3-acetic acid-amido synthetase 3.8, OsGH3.8 \\
\hline 42 & Os01g0720400 & LOC_Os01g52230 & 2.7 & Inorganic pyrophosphatase 1 \\
\hline 43 & Os02g0764700 & & 2.7 & Ethylene-responsive transcription factor ERF109 \\
\hline 44 & Os01g0915000 & LOC_Os01g68650 & 2.7 & Protein of unknown function DUF506 \\
\hline
\end{tabular}


Table 1 List of early glutamate-responsive genes in rice roots (Continued)

\begin{tabular}{|c|c|c|c|c|}
\hline 45 & Os01g0121500 & LOC_Os01g03130 & 2.7 & Unknown \\
\hline $46^{\mathrm{a}}$ & Os02g0807900 & LOC_Os02g56380 & 2.7 & Wall-associated receptor kinase 21, OsWAK21 \\
\hline 47 & Os04g0543900 & LOC_Os04g45970 & 2.7 & Glutamate dehydrogenase 2, GDH2 \\
\hline 48 & Os03g0203700 & LOC_Os03g10640 & 2.7 & Calcium-transporting ATPase 2 \\
\hline 49 & Os12g0198200 & LOC_Os12g09640 & 2.7 & Phosphatase $2 \mathrm{C}$ family protein \\
\hline 50 & Os04g0463500 & LOC_Os04g38950 & 2.7 & Anthranilate synthase beta subunit 1 \\
\hline 51 & Os05g0540900 & LOC_Os05g46340 & 2.7 & Unknown \\
\hline 52 & Os08g0473900 & LOC_Os08g36910 & 2.7 & Alpha-amylase isozyme 3D \\
\hline 53 & Os01g0717000 & LOC_Os01g51920 & 2.7 & Choline kinase 2 \\
\hline 54 & Os07g0493800 & LOC_Os07g31190 & 2.7 & Wall-associated receptor kinase 71, OsWAK71 \\
\hline 55 & Os05g0181300 & LOC_Os05g08860 & 2.6 & Unknown \\
\hline 56 & Os11g0667700 & LOC_Os11g44560 & 2.6 & Protein kinase domain containing protein \\
\hline $57^{\mathrm{a}}$ & Os02g0205500 & LOC_Os02g11070 & 2.6 & 3-ketoacyl-CoA synthase 11 \\
\hline 58 & Os03g0290300 & LOC_Os03g18070 & 2.6 & Omega-3 fatty acid desaturase \\
\hline 59 & Os06g0201200 & LOC_Os06g10020 & 2.6 & Unknown \\
\hline 60 & Os01g0905200 & LOC_Os01g67810 & 2.6 & Exo70 exocyst complex subunit \\
\hline 61 & Os03g0268600 & LOC_Os03g16170 & 2.6 & Phosphatase 2C family protein \\
\hline 62 & Os04g0618700 & LOC_Os04g52780 & 2.6 & LRR receptor-like serine/threonine protein kinase FLS2 \\
\hline 63 & Os12g0556200 & LOC_Os12g36910 & 2.6 & Calmodulin binding protein $60 \mathrm{~B}$ \\
\hline 64 & Os11g0474533 & LOC_Os11g28470 & 2.5 & Unknown \\
\hline 65 & Os04g0119500 & LOC_Os04g02910 & 2.5 & Unknown \\
\hline 66 & Os12g0248600 & LOC_Os12g14540 & 2.5 & Unknown \\
\hline $67^{\mathrm{a}}$ & Os04g0194500 & LOC_Os04g11820 & 2.5 & ABC transporter $\mathrm{G}$ family member 28 \\
\hline 68 & Os04g0497000 & LOC_Os04g41960 & 2.5 & NADPH oxidoreductase \\
\hline 69 & Os03g0648600 & LOC_Os03g44636 & 2.5 & RING-H2 finger protein ATL44-like \\
\hline 70 & Os11g0154500 & LOC_Os11g05614 & 2.5 & NAC-domain containing protein 90 \\
\hline $71^{\mathrm{a}}$ & Os02g0585100 & LOC_Os02g37320 & 2.5 & Heavy metal transport domain containing protein \\
\hline 72 & Os09g0313600 & LOC_Os09g14450 & 2.4 & Disease resistance RPP13-like protein 4 \\
\hline 73 & Os08g0457000 & LOC_Os08g35560 & 2.4 & Unknown \\
\hline 74 & Os01g0776700 & LOC_Os01g56890 & 2.4 & Unknown \\
\hline 75 & Os11g0168600 & LOC_Os11g06780 & 2.4 & Leucine-rich repeat receptor protein kinase MSP1-like \\
\hline 76 & Os09g0455300 & LOC_Os09g28210 & 2.4 & bHLH transcription factor, similar to HECATE1 (HEC1) \\
\hline 77 & Os09g0484900 & LOC_Os09g31130 & 2.3 & Tonoplast dicarboxylate transporter \\
\hline 78 & Os09g0452900 & LOC_Os09g27950 & 2.3 & Beta-1,3-galactosyltransferase 7 \\
\hline 79 & Os03g0292100 & LOC_Os03g18150 & 2.3 & Phosphatase $2 \mathrm{C}$ family protein \\
\hline 80 & Os05g0493100 & LOC_Os05g41370 & 2.3 & Cysteine-rich receptor-like protein kinase 15 \\
\hline 81 & Os11g0228600 & LOC_Os11g12240 & 2.2 & Similar to NBS-LRR disease resistance protein \\
\hline 82 & Os04g0490500 & LOC_Os04g41310 & 2.2 & PTI1-like tyrosine-protein kinase 3 \\
\hline 83 & Os03g0194600 & LOC_Os03g09880 & 2.2 & Cyt b561 and DOMON domain-containing protein \\
\hline 84 & Os01g0134700 & LOC_Os01g04280 & 2.2 & Calmodulin binding protein \\
\hline 85 & Os02g0661100 & LOC_Os02g44230 & 2.2 & Trehalose-6-phosphate phosphatase \\
\hline 86 & Os10g0521900 & LOC_Os10g37760 & 2.2 & Rhomboid-like protease, OsRhmbd17 \\
\hline 87 & Os08g0384500 & LOC_Os08g29570 & 2.2 & ABC transporter $\mathrm{G}$ family member 44 \\
\hline 88 & Os03g0218400 & LOC_Os03g11900 & 2.2 & Sugar transport protein 2 \\
\hline 89 & Os04g0461600 & LOC_Os04g38790 & 2.2 & Cell number regulator 2 \\
\hline
\end{tabular}


Table 1 List of early glutamate-responsive genes in rice roots (Continued)

\begin{tabular}{|c|c|c|c|c|}
\hline 90 & Os02g0627100 & LOC_Os02g41680 & 2.2 & Phenylalanine ammonia-lyase \\
\hline 91 & Os03g0407900 & LOC_Os03g29410 & 2.2 & Serine/threonine protein kinase \\
\hline 92 & Os07g0502200 & LOC_Os07g31884 & 2.2 & MATE efflux protein family protein \\
\hline 93 & Os02g0562600 & LOC_Os02g35490 & 2.2 & MLO-like protein 1 \\
\hline 94 & Os04g0634700 & LOC_Os04g54200 & 2.1 & Diacylglycerol kinase 5 \\
\hline 95 & Os01g0882800 & LOC_Os01g66010 & 2.1 & Amino acid permease 8 , AAP8 \\
\hline 96 & Os07g0232800 & LOC_Os07g12890 & 2.1 & Zinc transporter 8 \\
\hline $97^{\mathrm{a}}$ & Os09g0482800 & LOC_Os09g30490 & 2.1 & Calcium-binding EF-hand domain containing protein \\
\hline 98 & Os03g0773300 & LOC_Os03g56250 & 2.1 & LRR receptor-like serine/threonine protein kinase \\
\hline 99 & Os01g0934400 & LOC_Os01g70820 & 2.1 & Photosystem II oxygen evolving complex protein PsbP \\
\hline $100^{a}$ & Os08g0138200 & LOC_Os08g04370 & 2.1 & Cupredoxin domain containing protein, phytocyanin \\
\hline 101 & Os01g0690800 & LOC_Os01g49614 & 2.1 & Acidic endochitinase SE2 \\
\hline 102 & Os03g0792800 & LOC_Os03g57880 & 2.1 & Glucan endo-1,3-beta-glucosidase 8 \\
\hline 103 & Os05g0541100 & LOC_Os05g46350 & 2.1 & IQ calmodulin-binding region domain containing protein \\
\hline 104 & Os01g0817000 & LOC_Os01g60110 & 2.1 & Protein of unknown function DUF607 \\
\hline 105 & Os01g0723800 & LOC_Os01g52550 & 2.1 & ABC transporter $B$ family member 8 \\
\hline 106 & Os07g0561800 & LOC_Os07g37454 & 2.1 & Organic cation/carnitine transporter 2 \\
\hline 107 & Os01g0713200 & LOC_Os01g51570 & 2.1 & Glucan endo-1,3-beta-glucosidase GII \\
\hline 108 & Os02g0126400 & LOC_Os02g03410 & 2.1 & Calcium-dependent protein kinase 16 \\
\hline $109^{a}$ & Os07g0119300 & LOC_Os07g02800 & 2.1 & MYB domain containing protein \\
\hline 110 & Os02g0682300 & LOC_Os02g45780 & 2.1 & E3 ubiquitin-protein ligase RHA1B \\
\hline 111 & Os07g0583600 & LOC_Os07g39470 & 2.1 & Chitin-inducible gibberellin-responsive protein 2, CIGR2 \\
\hline $112^{\mathrm{a}}$ & Os11g0184900 & LOC_Os11g08210 & 2.0 & NAC domain-containing protein 5, OsNAC5 \\
\hline 113 & Os01g0570800 & LOC_Os01g38980 & 2.0 & IQ calmodulin-binding region domain containing protein \\
\hline 114 & Os10g0466800 & LOC_Os10g32930 & 2.0 & Unknown \\
\hline 115 & Os04g0632100 & LOC_Os04g53998 & 2.0 & Receptor-like serine/threonine-protein kinase SD1-6 \\
\hline 116 & Os06g0288100 & LOC_Os06g18000 & 2.0 & Leucine-rich repeat receptor-like protein kinase SOBIR1 \\
\hline 117 & Os02g0299300 & LOC_Os02g19650 & 2.0 & Putative aminoacrylate hydrolase RutD \\
\hline $118^{\mathrm{a}}$ & Os07g0589000 & LOC_Os07g40000 & 2.0 & LOB domain containing protein, LBD37-like \\
\hline 119 & Os03g0285800 & LOC_Os03g17700 & 2.0 & MAP Kinase 5 \\
\hline 120 & Os06g0292400 & LOC_Os06g18900 & 2.0 & Unknown \\
\hline 121 & Os08g0492500 & LOC_Os08g38460 & 2.0 & Probable E3 ubiquitin-protein ligase XERICO \\
\hline $122^{a}$ & Os08g0386200 & LOC_Os08g29660 & 2.0 & WRKY69 \\
\hline
\end{tabular}

Total RNA extracted from 17-day-old rice seedlings grown in hydroponic solution without nitrogen (-N) or treated with $2.5 \mathrm{mM}$ glutamate for $30 \mathrm{~min}(+\mathrm{Glu})$ was used for microarray analysis. ${ }^{a}$ Indicates genes that are also rapidly induced by glutamine [33]. The results were derived from two biological replicates

dependence of these genes to glutamate. For instance, the expression of Os09g0401000 (MYB family protein), Os04g0301500 (bHLH35) and Os02g0764700 (ERF109) was very sensitive to glutamate as treatment of $0.1 \mathrm{mM}$ glutamate for $30 \mathrm{~min}$ resulted in greater than 5-fold induction in these genes as compared to the untreated control (Fig. 4). The other genes that are sensitive to glutamate induction include Os03g0236200 (GDC1), Os01g0705200 (late embryogenesis abundant protein), Os12g0181500 (amino acid permease 3), Os02g0687200 (unknown), Os07g0592600 (OsGH3.8), Os01g0720400 (inorganic pyrophosphatase 1), Os11g0474533 (unknown), Os02g0627100 (phenylalanine ammonia-lyase), and Os09g0482800 (EF-hand domain containing protein). The expression of these genes was strongly induced by $0.1 \mathrm{mM}$ glutamate and stayed at high levels ( $>5$-fold) or continued to increase when treated with higher concentrations of glutamate as compared to the untreated control (Additional file 1: Figure S3). 


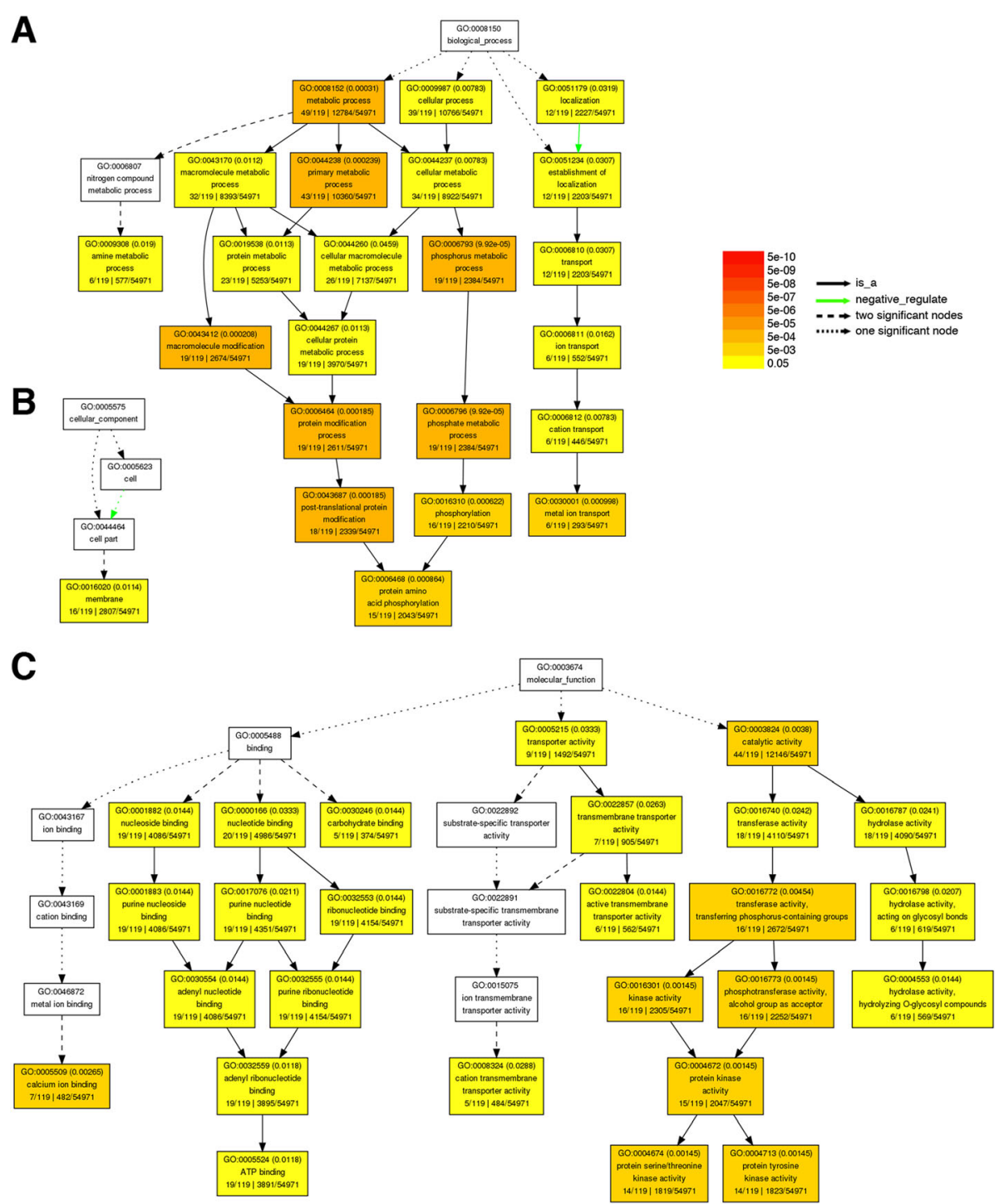

Fig. 3 Gene ontology enrichment analysis of genes up-regulated by glutamate. The differentially expressed genes were analyzed by singular enrichment analysis using AgriGO. Significantly enriched GO categories in biological process (a), cellular component (b), and molecular function (c) are shown in yellow, orange, and red boxes (false discovery rate, FDR < 0.05). Each box contains GO term number, the FDR value, GO term, and number associated with the GO term in the query list and glutamate up-regulated genes (119 GO terms) as well as total number of query list and reference background (54971 GO terms). The GO terms "primary metabolic process", "transporter activity" and "protein kinase activity" are significantly enriched in glutamate-responsive genes

\section{Regulation of glutamate-responsive transcription factor genes by different nitrogen}

To further examine if the response was specific to glutamate, we compared the effects of glutamate, glutamine, and ammonium nitrate on the expression of 11 glutamate-responsive transcription factor genes. Total RNA extracted from nitrogen-starved rice seedlings treated with $2.5 \mathrm{mM}$ glutamate, glutamine, or $1.43 \mathrm{mM}$ ammonium nitrate for $15 \mathrm{~min}$ to $24 \mathrm{~h}$ was used for qRTPCR analysis. The results revealed that glutamine and ammonium nitrate could rapidly induce the expression of many glutamate-responsive transcription factor genes in the roots (Fig. 5). Among these transcription factor genes, the expression of bHLH35 (Os04g0301500) was rapidly and strongly induced by glutamate ( $\sim 90$-fold, $15 \mathrm{~min}$; 160-fold, $30 \mathrm{~min}$; 230-fold, $1 \mathrm{~h}$ ) but was not or only slightly induced by glutamine and ammonium nitrate (Fig. 5a). The expression of MYB (Os09g0401000), bHLH13 (Os01g0705700) and NAC90 (Os11g0154500) was preferentially induced by glutamate within 15-30 min of treatments (Fig. 5a). By contrast, the expression of another $M Y B$ (Os07g0119300) was rapidly and preferentially induced by ammonium nitrate (Fig. 5b). The expression of CIGR2 (Os07g0583600) was strongly induced by ammonium 


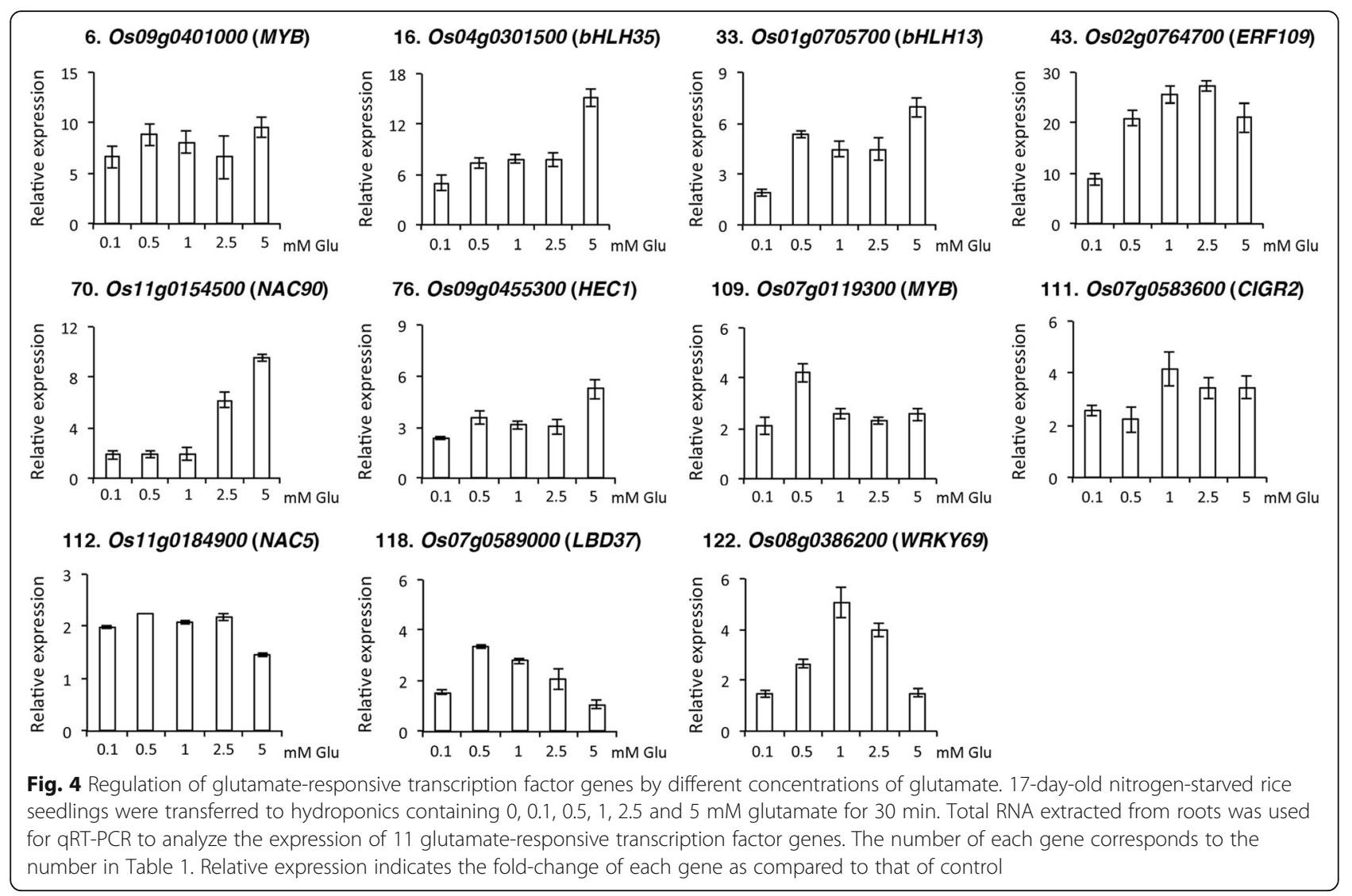

nitrate after treatment for $30 \mathrm{~min}$ (Fig. 5b). Although the expression of NAC5 (Os11g0184900) and WRKY69 (Os08g0386200) was induced by all nitrogen treatments, ammonium nitrate seemed to have stronger effects on the induction of these genes (Fig. 5b). While ammonium nitrate had little effect on the induction of ERF109 (Os02g0764700), glutamate and glutamine rapidly and strongly induced the expression of ERF109 (Fig. 5c). The expression of HEC1 (Os09g0455300) and LBD37 (Os07g0589000) was preferentially induced by glutamine (Fig. 5c).

\section{Identification of genes that are specifically induced by glutamate}

The discovery that the expression of bHLH35 (OsO4gO 301500), MYB (Os09g0401000), bHLH13 (Os01g0705700) and NAC90 (Os11g0154500) was specifically or preferentially induced by glutamate prompted us to examine the expression of the other 111 glutamate-responsive genes under glutamate, glutamine and ammonium nitrate time course treatments. The expression of many glutamateresponsive genes was also rapidly induced by glutamine and ammonium nitrate as compared with that of nitrogenstarved rice seedlings (Additional file 1: Figure S4). However, the expression patterns and the amounts of transcripts accumulated in response to different nitrogen sources varied from gene to gene. Of the additional 111 genes examined, the expression of at least 12 genes was strongly and preferentially induced by glutamate (Fig. 6). Interestingly, except the unknown function genes, most of the genes preferentially induced by glutamate, e.g. Os08g0508800 (HI-LOX), Os01g0666000 (lipid phosphate phosphatase 2), Os10g0542900 (chitinase 8), Os09g0471800 (WAK 85), Os03g0203700 (calcium transporting ATPase 2), Os12g0198200 (phosphatase 2C), are related to signal transduction or defense responses (Fig. 6a).

The expression of Os12g0518200 (EamA-like transporter) and Os01g0905300 (exocyst 70 subunit) was rapidly and preferentially induced by glutamate (Fig. 6b). The functions of these two genes are related to transport and secretion. The expression of at least 4 unknown function genes, e.g. Os04g0618400, Os01g0952900, Os03g0302800 and Os12g0248600, was specifically or preferentially induced by glutamate (Fig. 6c).

\section{Glutamate rapidly induces the expression of GDC1}

It is interesting that the expression of OsO3g0236200 (GDC1) has the strongest induction (9.6-fold) by glutamate in the microarray analysis (Table 1). Treatment of different concentrations of glutamate (0.1-5 mM, 


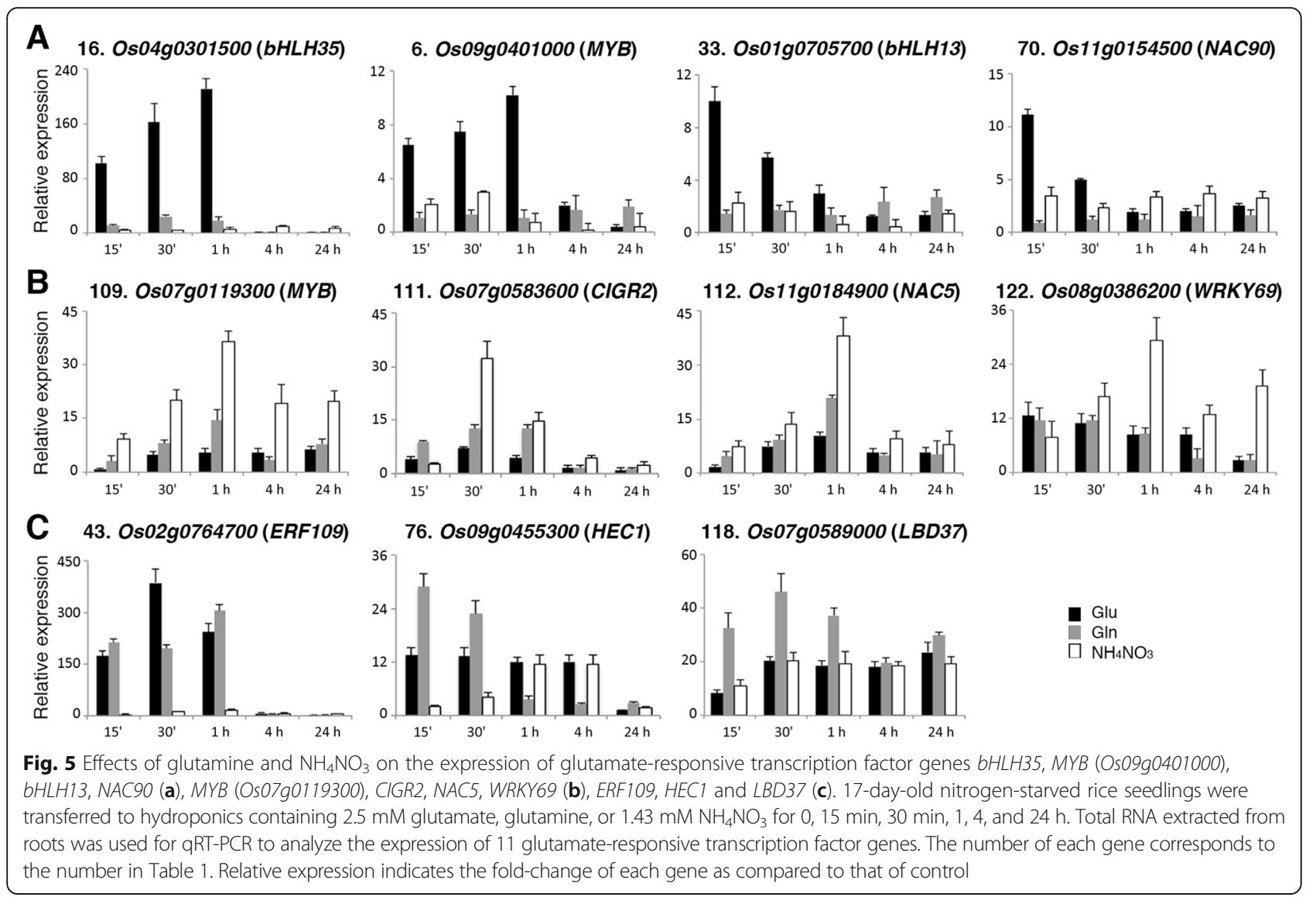

$30 \mathrm{~min}$ ) revealed that the expression of $G D C 1$ was very sensitive to glutamate as treatment of $0.1 \mathrm{mM}$ glutamate already significantly induced the expression of GDC1 (5.8-fold) as compared to the untreated control in the roots (Fig. 7a). Furthermore, the effect of glutamate on the induction of GDC1 is dosage dependent, e.g. the induction is stronger as the concentration of glutamate increases (Fig. 7a). In addition, the results of glutamate time course treatments revealed that glutamate rapidly and strongly induced the expression of GDC1 (Fig. 7b). The amount of GDC1 transcripts increased approximately $20-30$ folds after $0.5-1 \mathrm{~h}$ of $2.5 \mathrm{mM}$ glutamate treatment as compared to the levels of the untreated control (Fig. 7b). The function of GDC is to convert glutamate to GABA. To further examine if the induction of $G D C 1$ might contribute to the accumulation of GABA, we measured the amount of GABA in the seedlings during the time course of glutamate treatment. In contrast to the rapid induction of the GDC1 gene, the content of GABA did not increase significantly after 0.25 to $8 \mathrm{~h}$ of glutamate treatments as compared to the levels of the untreated control in the roots. The amount of GABA increased significantly ( 5-7 folds) until 16 to 24 h of glutamate treatments (Fig. 7c).

\section{Discussion}

Nutritional effect of glutamate on rice

Although glutamate and glutamine are closely related, exogenous glutamine appears to be more effective than glutamate in supporting rice seedling growth. We previously showed that supplementation of $0.1 \mathrm{mM}$ glutamine could significantly improve the growth of rice seedlings in hydroponics [33]. Here, we demonstrated that feeding of $0.1 \mathrm{mM}$ glutamate had little effect and supplementation of $0.5 \mathrm{mM}$ glutamate could significantly enhance rice seedling growth comparable to that of $0.1 \mathrm{mM}$ glutamine (Fig. 1) [33]. The optimal concentration of exogenous glutamate to support rice seedling growth is around 0.5-1 mM. When the supplemented glutamate exceeds this amount, the excess glutamate will inhibit the growth of rice seedlings. Together, these results support the notion that glutamate can serve as a nitrogen nutrient, but it is not as effective as ammonium nitrate or glutamine.

As leaf nitrogen content and chlorophyll concentration are closely linked, the level of leaf chlorophyll is commonly used as an indicator of endogenous nitrogen status. The chlorophyll contents in rice seedlings grown in $2.5-10 \mathrm{mM}$ glutamate were similar to those grown in ammonium nitrate. These results suggest that the rice seedlings grown in 2.5-10 mM glutamate can efficiently synthesize chlorophylls 

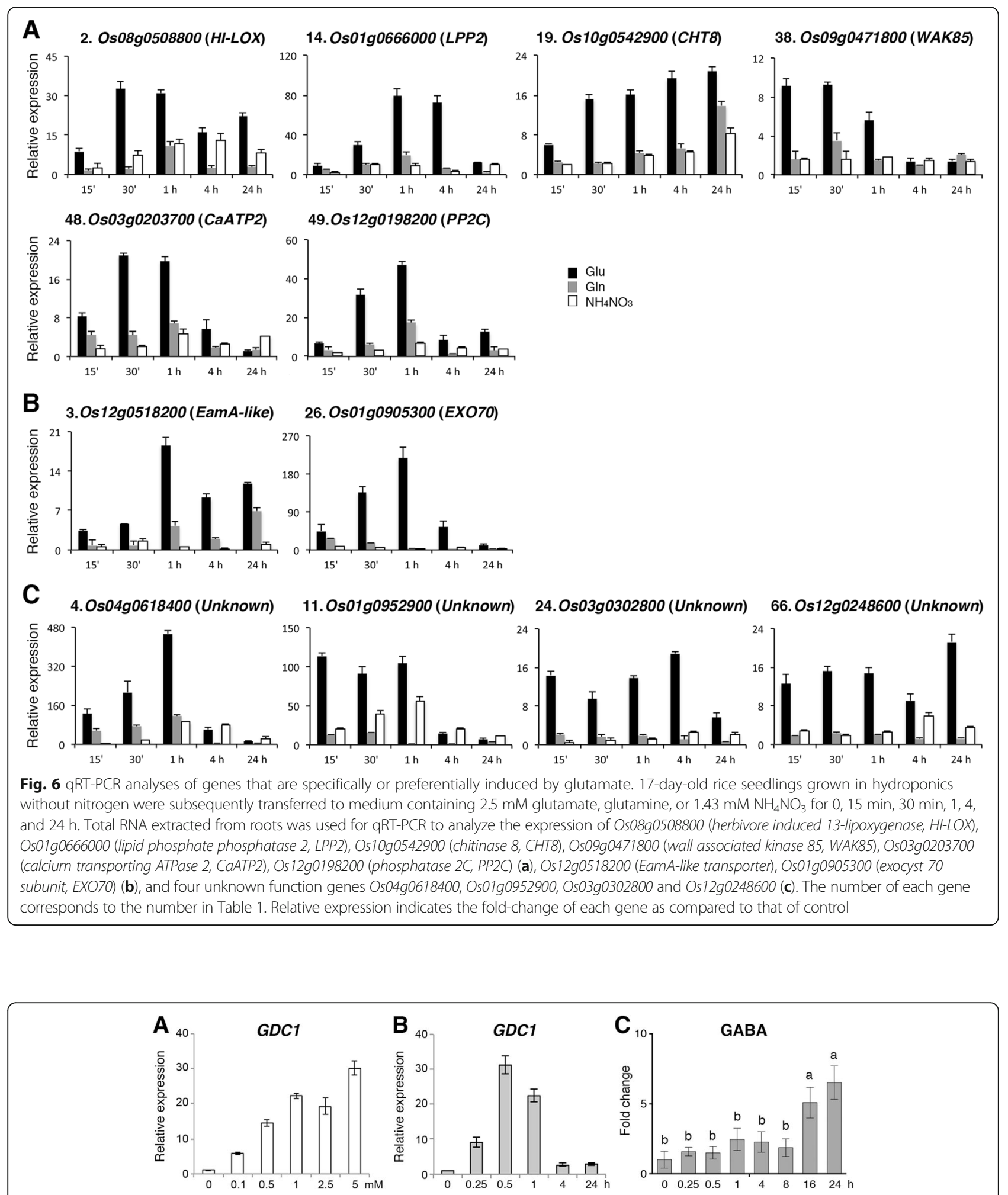

Fig. 7 Effects of glutamate on the expression of GDC1 and accumulation of GABA. qRT-PCR analysis of GDC1 from roots of 17-day-old rice seedlings treated with different concentrations of glutamate for $30 \mathrm{~min}(\mathbf{a})$, or treated with $2.5 \mathrm{mM}$ glutamate for $0.25-24 \mathrm{~h}$ (b). Relative expression indicates the fold-change of each gene as compared to that of control. c The amounts of GABA in the roots. 17-day-old nitrogen-starved rice seedlings were transferred to hydroponics containing $2.5 \mathrm{mM}$ glutamate for $24 \mathrm{~h}$. The amounts of GABA in the roots were measured during the time course of glutamate treatments. Fold change indicates the relative amount of GABA compared to that of control $(0 \mathrm{~h})$. Data are means \pm SD $(n=4)$. Different letters indicate significant differences between treatments, tested by one-way ANOVA followed by Tukey's test $(P<0.05)$ 
and do not have symptoms of nitrogen deficiency. Thus, the inhibitory effects of $2.5-10 \mathrm{mM}$ glutamate on the growth of rice seedling are likely caused by over nutrition or glutamate toxicity, rather than nitrogen deficiency.

We previously showed that glutamine could be rapidly taken up by nitrogen-starved rice seedlings and was almost used up in hydroponics after $24 \mathrm{~h}$ of feeding [33]. Here, we performed a similar experiment and found that nitrogenstarved rice seedlings could not consume glutamate as effectively as glutamine. After feeding of glutamate to nitrogen-starved rice seedlings for $24 \mathrm{~h}$, approximately $50 \%$ of the supplemented glutamate was still left in the growth medium (Fig. 2a). These results suggest that rice seedlings may have different mechanisms to absorb glutamine and glutamate. In Arabidopsis, four amino acid transporters, e.g. AAP1, AAP5, ProT2, and LHT1, have been shown to play a role in amino acid uptake by the root [46]. By contrast, amino acid transporters have been rarely studied in monocots [47]. Recently, analysis of rice amino acid permeases reveals that OsAAP1, OsAAP7 and OsAAP16 function as general amino acid permeases and transport all amino acids well except aspartate and $\beta$-alanine, whereas OsAAP3 has a distinct substrate specificity that prefers neutral and basic amino acids [48]. Interestingly, these rice AAPs all have better specificity to glutamine than glutamate [48]. It is likely that rice roots may have a more efficient transport system to take up glutamine than glutamate, which is consistent with our hydroponic feeding results.

\section{Glutamate homeostasis in rice seedlings}

Glutamate is the most abundant free amino acid in nitrogen-starved rice seedlings (Additional file 1: Figure S2). Interestingly, feeding of $2.5 \mathrm{mM}$ glutamate to nitrogenstarved rice seedlings did not significantly increase the amount of endogenous glutamate within the first hour. The glutamate content increased to approximately 2.5-fold of control after 4-24 h of feeding, which are relatively small as compared to those of glutamine ( 10 -fold) and GABA ( 7-fold), two nitrogen-containing compounds directly linked to glutamate metabolism. Asparagine is a relative inert amino acid. Levels of asparagine increased to $\sim 20$-fold of control after $24 \mathrm{~h}$ of glutamate feeding. Asparagine and glutamine have high nitrogen to carbon ratios that play important roles in nitrogen storage and transport in plants. The accumulation of these amino acids indicates that the rice seedlings are not deficient of nitrogen after several hours of glutamate feeding.

We previously showed that feeding of glutamine to nitrogen-starved rice seedlings resulted in rapid and dramatic accumulation of glutamine, but not glutamate, in the roots [33]. Here, we demonstrated that feeding of glutamate also resulted in dramatic increases of glutamine, but not glutamate. These results suggest that glutamate, a very active amino acid, either directly absorbed from the environment or derived from glutamine, will be quickly metabolized to other nitrogen-containing compounds in plants. In addition to its critical role in metabolism, glutamate may also function as a signaling molecule to regulate plant growth and development. Thus, it is important for plants to maintain the homeostasis of glutamate as dramatic fluctuations of glutamate may have detrimental effects on plant metabolism, growth and development. It is not clear how plants maintain the homeostasis of glutamate. The rapid induction of glutamate metabolic genes such as GDC1 (Os03g0236200) and GDH2 (Os04g0543900) observed in this study may represent one of the strategies to maintain glutamate homeostasis. Still, other mechanisms involved in the regulation of glutamate homeostasis have yet to be uncovered in plants.

\section{Glutamate can trigger an elicitor-like response in plants}

It is unexpected that many genes related to defense responses are rapidly induced by glutamate. For instance, the elicitor-responsive gene CIGR2 encodes a transcriptional activator that is involved in hypersensitive response during pathogen infection [36]. The JA responsive gene bHLH35 (RERJ1) is involved in disease resistance and drought tolerance [41, 49]. Herbivore-induced 13-lipoxygenase (OsHI-LOX) has been demonstrated to be involved in defense response [50]. The indole-3-acetic acid-amido synthetase GH3.8 is involved in salicylateand jasmonate-independent basal immunity in rice [45]. Several wall-associated kinases are involved in basal defense against rice blast fungus [44]. Glutamate rapidly induced the expression of CIGR2, OsHI-LOX, OsGH3.8, $W A K s$ and defense-related genes encoding trypsin inhibitor, xylanase inhibitor, aspartic proteinase, subtilisinlike protease, chitinase, and disease-related receptor-like protein kinases (Table 1). Glutamate also rapidly induced the expression of stress-related genes encoding late embryogenesis abundant (LEA) protein, E3 ubiquitinprotein ligase, heavy metal transport domain-containing protein, MATE efflux protein, phytocyanin, and glycosyl hydrolase (Table 1). The rapid induction of these defenseand stress-related genes suggests that glutamate may trigger an elicitor-like response in rice seedlings.

Interestingly, exogenous glutamate has been shown to induce systemic disease resistance in rice [26]. It is conceivable that glutamate may have a role similar to an elicitor or the exogenous glutamate may affect the cell wall and triggers an elicitor-like response in the plant cell. Glutamate or changes in the cell wall caused by exogenous glutamate may be perceived by receptor or sensor proteins located on the cell surface, which in turn transmit the signal to the nucleus to regulate the expression of defense-related genes. Alternatively, the endogenous glutamate or metabolites derived from glutamate may be directly involved in the regulation of defense-related genes. 
In addition to defense and stress-related genes, glutamate also rapidly induced the expression of genes involved in metabolism, transport, growth and signal transduction.

Some of the early glutamate-responsive genes encode membrane/wall receptors, transporters, calcium signaling proteins, protein kinases/phosphatases, and transcription factors (Table 1, Additional file 1: Table S2), which may be involved in glutamate sensing and signaling in rice roots. Although the expression of glutamate receptor genes is not rapidly induced by glutamate (Additional file 1: Table S5), we cannot exclude the possibility that the glutamate signaling pathways are mediated by GLRs to regulate gene expression in rice roots. Still, glutamate may employ its signaling functions through GLR independent pathways. Some of the early glutamateresponsive genes identified in this study may be involved in the GLR dependent or independent pathways.

\section{Interactions between glutamate and glutamine signaling pathways}

Glutamate and glutamine are closely related in structure and metabolism. Although glutamine is more effective in serving as a nitrogen nutrient, glutamate has more profound effects on the regulation of gene expression in rice seedlings. Glutamine rapidly induces the expression of 35 genes [33], whereas glutamate induces the expression of at least 122 genes in rice roots. Some of the glutamate-induced genes are specifically related to glutamate metabolism and transport. For instance, the expression of GDH2 and several transporter genes is induced by glutamate (Table 1). Glutamine induces the expression of glutamine dumper genes [33], which are not induced by glutamate. An unexpected common theme is that both glutamate and glutamine rapidly induce the expression of stress response genes. Glutamate, in particular, affects more genes related to defense function. Further studies on this newly emerging theme, e.g. amino acids and defense response, promise to provide new insights into the molecular mechanism of amino acid signaling in plants.

Still, the microarray data revealed that glutamate and glutamine commonly induced the expression of 17 genes (Table 1). Most of the commonly induced genes are not directly involved in metabolism. Interestingly, 5 of the 17 commonly induced genes encode putative transcription factors, e.g. bHLH35 (Os04g0301500), MYB (Os07g0119300), NAC5 (Os11g0184900), LBD37-like (Os07g0589000), and WRKY69 (Os08g0386200). It is possible that glutamate and glutamine may share some components in the signaling pathways to regulate plant growth and stress responses. Alternatively, some of the glutamate effects may be indirectly caused by glutamine as treatment of exogenous glutamate rapidly and significantly increases the amount of endogenous glutamine. Nevertheless, we have identified several genes that are specifically or preferentially induced by glutamate (Figs. 5, 6 and Additional file 1: Figure S4). These genes can be used to dissect the molecular mechanism of glutamate signaling and regulation of gene expression in the future.

\section{Significance of exogenous glutamate treatment}

Nitrate and ammonium have been considered as the dominant nitrogen sources for plants and research on plant nitrogen nutrition has thus heavily focused on these inorganic nitrogen forms. One of the reasons that drives many researchers to study the effects of nitrate and ammonium on plants is the use of inorganic nitrogen fertilizers in agriculture. In fact, organic and inorganic nitrogen sources coexist in the ecosystem, and plants can use a diverse array of nitrogen forms, including amino acids, present in the soil [51]. It has been shown that Arabidopsis roots can take up amino acids at naturally occurring concentrations from agricultural soil $[52,53]$. Under natural conditions, decomposing organic matters including plant and animal tissues may result in organic nitrogen-rich patches in the soil. Although glutamate concentrations are normally low $(<10 \mu \mathrm{M})$ in bulk soil solutions [54], high concentrations of glutamate may routinely occur in organic nitrogen-rich patches as plant and animal tissues contain free glutamate at millimolar levels $[55,56]$. The concentrations of apoplastic glutamate has been reported in the range of 0.3-1.3 $\mathrm{mM}$ in a variety of tissues and plant species [57-61]. Interestingly, some of the glutamate-responsive genes identified here can be rapidly induced ( $30 \mathrm{~min}$ ) by exogenous glutamate at a relatively low concentration $(0.1 \mathrm{mM})$. These results suggest that the signaling role of glutamate in the regulation of gene expression may occur in planta.

\section{Conclusion}

Glutamate is a very active amino acid that occupies a central position in the primary metabolism in plants. Here, we show that glutamate, the most abundant amino acid in nitrogen-starved rice seedlings, may play a role in plant nutrition and function as a signaling molecule to regulate gene expression. In addition to genes involved in metabolism, transport, growth and signal transduction, glutamate rapidly induces the expression of genes related defense and stress responses. The elicitor-like response triggered by glutamate may partly explain the effect of exogenous glutamate on the induction of disease resistance in rice. The nutritional effects and the diverse functions of early glutamate-responsive genes support the notion that glutamate is an important metabolic fuel and a functional amino acid in plants. 


\section{Methods}

\section{Plant material and growth conditions}

Rice (Oryza sativa L. ssp. Japonica cv. TNG67) seeds were germinated in darkness at $30{ }^{\circ} \mathrm{C}$ for 3 days. The etiolated rice seedlings were cultured in hydroponic solutions [62] containing modified nitrogen sources, with $(+\mathrm{N})$ or without $(-\mathrm{N}) 1.43 \mathrm{mM} \mathrm{NH}_{4} \mathrm{NO}_{3}$, or supplemented with $0.1-10 \mathrm{mM}$ glutamate, in a controlled growth chamber at $30{ }^{\circ} \mathrm{C}$ under a 12-h light/12-h dark photoperiod with $200 \mu \mathrm{mol}$ photons $\mathrm{m}^{-2} \mathrm{~s}^{-1}$ light intensity and 70\% relative humidity for 2 weeks. The hydroponic solution was renewed every 3 days in all experiments. The hydroponic solution recommended by The International Rice Research Institute contains $1.43 \mathrm{mM} \mathrm{NH}_{4} \mathrm{NO}_{3}$ [62], which was used as a control $(+\mathrm{N})$ in all experiments conducted in this study.

\section{Measurement of chlorophyll content}

The Chlorophyll Content Meter (CCM-300, Opti-sciences, $\mathrm{NH}$, USA) was used to measure the amount of chlorophyll in leaves of 17-day-old rice seedlings grown in hydroponic solutions $+\mathrm{N}$, $-\mathrm{N}$, or supplemented with $0.1-10 \mathrm{mM}$ glutamate as the sole nitrogen source.

\section{RNA isolation and microarray analysis}

Total RNA extracted from roots and shoots of 17-dayold rice seedlings grown in hydroponic solution -N or $+2.5 \mathrm{mM}$ glutamate for $30 \mathrm{~min}$ was used for microarray analysis with the GeneChip Rice Genome Array (Affymetrix, Santa Clara, CA, USA). The method for total RNA isolation was as described previously [63]. RNA samples from two biological repeats were used for the microarray experiment conducted by the Affymetrix Gene Expression Service Lab at Academia Sinica, Taipei, Taiwan (http://ipmb.sinica.edu.tw/affy/). Target preparation, hybridization, washes, staining, array scanning, and data analysis were performed as described [33]. Two-fold cutoff and a $P$-value less than 0.05 were applied to select for up- and down-regulated genes after $2.5 \mathrm{mM}$ Glu treatment for $30 \mathrm{~min}$. AgriGO [64] was used to perform the gene ontology (GO) analysis of 122 glutamate up-regulated genes compared with the genome-wide background with an adjusted $p$-value (False Discovery Rate, FDR) cutoff of 0.05 . The GO categories consisting of three structured networks, e.g. biological process, cellular component and molecular function, of defined terms were derived from Gene Ontology (www.geneontology.org). Kyoto Encyclopedia of Genes and Genomes (KEGG) analysis of 122 glutamate up-regulated genes was performed using BlastKOALA (http://www.kegg.jp/blastkoala/). A web-based program EXPath (http://expath.itps.ncku. edu.tw/enrichment/rice/enrichment_analysis.php) was used to analyze KEGG pathway enrichment with the thresholds of $P$-value $<0.05$ [65].

\section{Quantitative RT-PCR analysis of glutamate-responsive genes}

To examine the effect of different glutamate concentrations on the expression of glutamate-responsive genes, 17-day-old rice seedlings grown in $-\mathrm{N}$ hydroponics were transferred to solutions containing 0-5 mM glutamate for $30 \mathrm{~min}$. For the time course experiment with different nitrogen treatments, 17-day-old rice seedlings grown in $-\mathrm{N}$ hydroponics were transferred to solutions containing $2.5 \mathrm{mM}$ glutamate, glutamine, or $1.43 \mathrm{mM} \mathrm{NH}_{4} \mathrm{NO}_{3}$ for $0-24 \mathrm{~h}$. Total RNA extracted from roots of glutamatetreated rice seedlings was digested with DNase I and used for qRT-PCR analysis. All of the quantifications were normalized to the nuclear gene UBC3 (Os02g0634800). The primers used for qRT-PCR analysis are listed in Additional file 1: Table S6. The qRT-PCRs were performed in triplicate for each sample in three independent experiments.

\section{Amino acid and GABA analysis}

For amino acid and GABA analysis, 17-day-old rice seedlings grown in $-\mathrm{N}$ hydroponics were transferred to fresh $-\mathrm{N}$ or $-\mathrm{N}$ supplemented with $2.5 \mathrm{mM}$ glutamate for $30 \mathrm{~min}$ or the indicated time. Roots and shoots were harvested separately amino acid extraction. The method for amino acid extraction was described previously [33]. Amino acid samples from four biological repeats were analyzed using the Waters Acquity UPLC system equipped with a Waters AccQ•Tag Ultra column $(2.1 \mathrm{~mm} \times 10 \mathrm{~mm}$, $1.7 \mu \mathrm{m}$ particles) as described [33].

\section{Additional file}

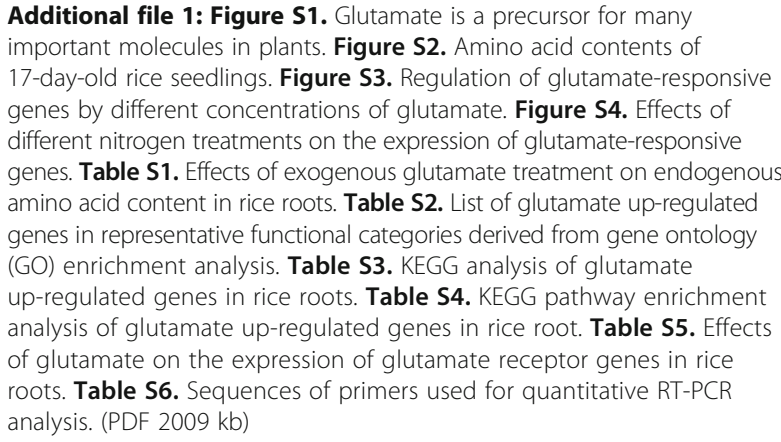

\section{Abbreviations}

GABA: -aminobutyrate; GDC: Glutamate decarboxylase; GDH: Glutamate dehydrogenase; GLR: Glutamate receptor; GO: Gene ontology; GOGAT: Glutamineoxoglutarate aminotransferase; GS: Glutamine synthetase; GSH: Glutathione; HI-LOX: Herbivore induced 13-lipoxygenase; KEGG: Kyoto encyclopedia of genes and genomes; KO: KEGG orthology; qRT-PCR: Quantitative reverse transcriptionpolymerase chain reaction; WAK: Wall associated kinase

\section{Acknowledgements}

We thank Chun-Ling Sung, Shi-Kat Wong, Wei-Yu Hsieh and Ying-Jhu Chen for technical assistance. 


\section{Funding}

This research was supported by a grant (AS-103-SS-A03) from Academia Sinica, Taipei, Taiwan.

\section{Availability of data and materials}

The dataset supporting the results of this article is available in the NCBI GEO repository [http://www.ncbi.nlm.nih.gov/geo/query/acc.cgi?acc=GSE82277].

\section{Authors' contributions}

CCK, TYC and MHH conceived and designed the experiments. CCK, TYC, HYW and YAJ conducted the experiments and analyzed the data. $\mathrm{MHH}$ wrote the paper. All authors read and approved the final manuscript.

\section{Competing interests}

The authors declare that they have no competing interests.

\section{Consent for publication}

Not applicable.

\section{Ethics approval and consent to participate}

Not applicable.

Received: 2 July 2016 Accepted: 13 February 2017

Published online: 17 February 2017

\section{References}

1. Lea PJ, Miflin BJ. Alternative route for nitrogen assimilation in higher plants. Nature. 1974;251:614-6.

2. Lam HM, Coschigano K, Schultz C, Oliveira R, Tjaden G, Oliveira I, Ngai N Hsieh MH, Coruzzi G. Use of Arabidopsis mutants and genes to study amide amino acid biosynthesis. Plant Cell. 1995;7:887-98.

3. Tabuchi M, Abiko T, Yamaya T. Assimilation of ammonium ions and reutilization of nitrogen in rice (Oryza sativa L.). J Exp Bot. 2007;58:2319-27.

4. Foyer $\mathrm{CH}$, Bloom AJ, Queval G, Noctor G. Photorespiratory metabolism: genes, mutants, energetics, and redox signaling. Annu Rev Plant Biol. 2009;60:455-84.

5. Forde BG, Lea PJ. Glutamate in plants: metabolism, regulation, and signaling. J Exp Bot. 2007;58:2339-58.

6. Lu SC. Glutathione synthesis. Biochim Biophys Acta. 1830;2013:3143-53.

7. Shelp BJ, Bown AW, McLean MD. Metabolism and functions of gamma-aminobutyric acid. Trends Plant Sci. 1999:4:446-52.

8. Bouche N, Fromm H. GABA in plants: just a metabolite? Trends Plant Sci. 2004;9:110-5.

9. Bown AW, MacGregor KB, Shelp BJ. Gamma-aminobutyrate: defense against invertebrate pests? Trends Plant Sci. 2006;11:424-7.

10. Bouché N, Fait A, Zik M, Fromm H. The root specific glutamate decarboxylase (GAD1) is essential for sustaining GABA levels in Arabidopsis. Plant Mol Biol. 2004;55:315-25.

11. Ramesh SA, Tyerman SD, Xu B, Bose J, Kaur S, Conn V, et al. GABA signaling modulates plant growth by directly regulating the activity of plant-specific anion transporters. Nat Commun. 2015;6:7879.

12. Hanson AD, Gregory III JF. Folate biosynthesis, turnover, and transport in Plants. Annu Rev Plant Biol. 2011:62:105-25.

13. Traynelis SF, Wollmuth LP, McBain CJ, Menniti FS, Vance KM, Ogden KK, et al. Glutamate receptor ion channels: structure, regulation, and function. Pharmacol Rev. 2010;62:405-96.

14. Hinoi E, Takarada T, Ueshima T, Tsuchihashi Y, Yoneda Y. Glutamate signaling in peripheral tissues. Eur J Biochem. 2004;271:1-13.

15. Ganor $Y$, Levite M. Glutamate in the immune system: glutamate receptors in immune cells, potent effects, endogenous production and involvement in disease. In: Levite $M$, editor. Nerve-driven immunity: neurotransmitters and neuropeptides in the immune system. Vienna: Springer Verlag; 2012. p. 121-61.

16. Featherstone DE. Intercellular glutamate signaling in the nervous system and beyond. Acs Chem Neurosci. 2010;1:4-12.

17. Lam HM, Chiu J, Hsieh MH, Meisel L, Oliveira IC, Shin M, Coruzzi G. Glutamate receptor genes in plants. Nature. 1998;396:125-6.

18. Chiu JC, Brenner ED, De Salle R, Nitabach MN, Holmes TC, Coruzzi GM Phylogenetic and expression analysis of the glutamate receptor-like gene family in Arabidopsis thaliana. Mol Biol Evol. 2002;19:1066-82.

19. Forde B. Glutamate signaling in roots. J Exp Bot. 2014;65:779-87.
20. Tapken D, Anschutz U, Liu LH, Huelsken T, Seebohm G, Becker D, Hollmann M. A plant homolog of animal glutamate receptors is an ion channel gated by multiple hydrophobic amino acids. Sci Signal. 2013;6:47.

21. Dennison KL, Spalding EP. Glutamate-gated calcium fluxes in Arabidopsis. Plant Physiol. 2000;124:1511-4.

22. Walch-Liu P, Liu L-H, Remans T, Tester M, Forde BG. Evidence that L-glutamate can act as an exogenous signal to modulate root growth and branching in Arabidopsis thaliana. Plant Cell Physiol. 2006;47:1045-57.

23. Forde BG, Walch-Liu P. Nitrate and glutamate as environmental cues for behavioral responses in plant roots. Plant Cell Environ. 2009;32:682-93.

24. Forde BG, Cutler S, Zaman N, Krysan PJ. Glutamate signalling via a MEKK1 kinase-dependent pathway induces changes in Arabidopsis root architecture. Plant J. 2013:75:1-10.

25. Rodriguez MC, Petersen M, Mundy J. Mitogen-activated protein kinase signaling in plants. Annu Rev Plant Biol. 2010;61:621-49.

26. Kadotani N, Akagi A, Takatsuji H, Miwa T, Igarashi D. Exogenous proteinogenic amino acids induce systemic resistance in rice. BMC Plant Biol. 2016;16:60.

27. Fritz C, Mueller C, Matt P, Feil R, Stitt M. Impact of the C-N status on the amino acid profile in tobacco source leaves. Plant Cell Environ. 2006;29:2055-76.

28. Schneidereit J, Hausler RE, Fien G, Kaiser W, Weber W, Weber APM. Antisense repression reveals a crucial role of the plastidic 2-oxoglutarate/ malate translocator DiT1 at the interface between carbon and nitrogen metabolism. Plant J. 2006:45:206-24.

29. Masclaux-Daubresse C, Carrayol E, Valadier MH. The two nitrogen mobilization- and senescence-associated GS1 and GDH genes are controlled by C and N metabolites. Planta. 2005;221:580-8.

30. Masclaux-Daubresse C, Reisdorf-Cren M, Pageau K, Lelandais M, Grandjean O, Kronenberger J, Valadier MH, Feraud M, Jouglet T, Suzuki A. Glutamine synthetase-glutamate synthase pathway and glutamate dehydrogenase play distinct roles in the sink-source nitrogen cycle in tobacco. Plant Physiol. 2006:140:444-56.

31. Ljungdahl PO. Amino-acid-induced signaling via the SPS-sensing pathway in yeast. Biochem Soc Trans. 2009;37:242-7.

32. Brasse-Lagnel C, Lavoinne A, Husson A. Control of mammalian gene expression by amino acids, especially glutamine. FEBS J. 2009;276:1826-44

33. Kan CC, Chung TY, Juo YA, Hsieh MH. Glutamine rapidly induces the expression of key transcription factor genes involved in nitrogen and stress responses in rice roots. BMC Genomics. 2015;16:731.

34. Kan CC, Chung TY, Hsieh MH. Gene expression profiling of rice seedlings in response to glutamine treatment. Genomics Data. 2015;6:123-4.

35. Rubin G, Tohge T, Matsuda F, Saito K, Scheible WR. Members of the LBD family of transcription factors repress anthocyanin synthesis and affect additional nitrogen responses in Arabidopsis. Plant Cell. 2009;21:3567-84.

36. Tanabe S, Onodera H, Hara N, Ishii-Minami N, Day B, Fujisawa Y, Hagio T, Toki S, Shibuya N, Nishizawa Y, Minami E. The elicitor-responsive gene for a GRAS family protein, CIGR2, suppresses cell death in rice inoculated with rice blast fungus via activation of a heat shock transcription factor, OsHsf23. Biosci Biotechnol Biochem. 2015:80:145-51.

37. Takasaki H, Maruyama K, Kidokoro S, Ito Y, Fujita Y, Shinozaki K, Yamaguchi-Shinozaki K, Nakashima K. The abiotic stress-responsive NAC-type transcription factor OsNAC5 regulates stress-inducible genes and stress tolerance in rice. Mol Genet Genomics. 2010;284:173-83.

38. Song SY, Chen Y, Chen J, Dai XY, Zhang WH. Physiological mechanisms underlying OsNAC5-dependent tolerance of rice plants to abiotic stress. Planta. 2011;234:331-45.

39. Jeong JS, Kim YS, Redillas MCFR, Jang G, Jung H, Bang SW, Choi YD, Ha SH, Reuzeau C, Kim JK. OsNAC5 overexpression enlarges root diameter in rice plants leading to enhanced drought tolerance and increased grain yield in the field. Plant Biotech J. 2013;11:101-14.

40. Kiribuchi K, Sugimori M, Takeda M, Otani T, Okada K, Onodera H, et al. RERJ1, a jasmonic acid-responsive gene from rice, encodes a basic helix-loop-helix protein. Biochem Biophys Res Commun. 2004;325:857-63.

41. Kiribuchi K, Jikumaru Y, Kaku H, Minami E, Hasegawa M, Kodama O, et al. Involvement of the basic helix-loop-helix transcription factor RERJ1 in wounding and drought stress responses in rice plants. Biosci Biotech Biochem. 2005;69:1042-4.

42. Miyamoto K, Shimizu T, Mochizuki S, Nishizawa Y, Minami E, Nojiri H, et al. Stress induced expression of the transcription factor RERJ1 is tightly regulated in response to jasmonic acid accumula- tion in rice. Protoplasma. 2013:250:241-9. 
43. Kohorn BD, Kohorn SL. The cell wall-associate kinases, WAKs, as pectin receptors. Front Plant Sci. 2012;3:88.

44. Delteil A, Gobbato E, Cayrol B, Estevan J, Michel-Romiti C, Dievart A, et al. Several wall-associated kinases participate positively and negatively in basal defense against rice blast fungus. BMC Plant Biol. 2016;16:17.

45. Ding X, Cao Y, Huang L, Zhao J, Xu C, Li X, Wang S. Activation of the indole-3-acetic acid-amido synthetase $\mathrm{GH} 3-8$ suppresses expansin expression and promotes salicylate- and jasmonate-independent basal immunity in rice. Plant Cell. 2008;20:228-40.

46. Tegeder M. Transporters involved in source to sink partitioning of amino acids and ureides: opportunities for crop improvement. J Exp Bot. 2014;65:1865-78.

47. Zhao H, Ma H, Yu L, Wang X, Zhao J. Genome-wide survey and expression analysis of amino acid transporter gene family in rice (Oryza sativa L.). PLoS One. 2012;7:e49210.

48. Taylor MR, Reinders A, Ward JM. Transport function of rice amino acid permeases (AAPs). Plant Cell Physiol. 2015;56:1355-63.

49. Jisha V, Dampanaboina L, Vadassery J, Mithöfer A, Kappara S, Ramanan R. Overexpression of an AP2/ERF type transcription factor OsEREBP1 confers biotic and abiotic stress tolerance in rice. PLoS One. 2015;10:e0127831.

50. Zhou G, Qi J, Ren N, Cheng J, Erb M, Mao B, Lou Y. Silencing OsHI-LOX makes rice more susceptible to chewing herbivores, but enhances resistance to a phloem feeder. Plant J. 2009;60:638-48.

51. Näsholm T, Kielland K, Ganeteg U. Uptake of organic nitrogen by plants. New Phytologist. 2009;182:31-48.

52. Svennerstam H, Jämtgård S, Ahmad I, Huss-Danell K, Näsholm T, Ganeteg U. Transporters in Arabidopsis roots mediating uptake of amino acids at naturally occurring concentrations. New Phytologist. 2011;191:459-67.

53. Ganeteg U, Ahmad I, Jämtgård S, Aguetoni-Cambui C, Inselsbacher E, Svennerstam H, Schmidt S, Näsholm T. Amino acid transporter mutants of Arabidopsis provides evidence that a non-mycorrhizal plant acquires organic nitrogen from agricultural soil. Plant Cell Environ. 2016. doi:10.1111/pce.12881.

54. Jones DL, Shannon D, Junvee-Fortune T, Farrar JF. Plant capture of free amino acids is maximized under high soil amino acid concentrations. Soil Biol Biochem. 2005;37:179-81.

55. Joy KW, Blackwell RD, Lea PJ. Assimilation of nitrogen in mutants lacking enzymes of the glutamate synthase cycle. J Exp Bot. 1992;43:139-45.

56. Young VR, Ajami AM. Glutamate: an amino acid of particular distinction. J Nutr. 2000;130:892S-900S

57. Lohaus G, Winter H, Riens B, Heldt HW. Further studies of the phloem loading process in leaves of barley and spinach-the comparison of metabolite concentrations in the apoplastic compartment with those in the cytosolic compartment and in the sieve tubes. Bot Acta. 1995;108:270-5.

58 Ruan YL, Patrick JW, Brady CJ. The composition of apoplast fluid recovered from intact developing tomato fruit. Aust J Plant Physiol. 1996;23:9-13.

59 Lohaus G, Heldt HW. Assimilation of gaseous ammonia and the transport of its products in barley and spinach leaves. J Exp Bot. 1997:48:1779-86.

60 Lohaus G, Pennewiss K, Sattelmacher B, Hussmann M, Muehling KH. Is the infiltration-centrifugation technique appropriate for the isolation of apoplastic fluid? A critical evaluation with different plant species. Physiol Plant. 2001;111:457-65.

61 Demidchik V, Essah PA, Tester M. Glutamate activates cation currents in the plasma membrane of Arabidopsis root cells. Planta. 2004;219:167-75.

62 Yoshida S, Forno D, Cock J, Gomez K. Laboratory manual for physiological studies of rice. Manila, The Philippines: The International Rice Research Institute; 1976

63 Tseng CC, Lee CJ, Chung YT, Sung TY, Hsieh MH. Differential regulation of Arabidopsis plastid gene expression and RNA editing in non-photosynthetic tissues. Plant Mol Biol. 2013:82:375-92

64 Du Z, Zhou X, Ling Y, Zhang Z, Su Z. AgriGO: a GO analysis toolkit for the agricultural community. Nucleic Acids Res. 2010:38:W64-70.

65 Chien CH, Chow CN, Wu NY, Chiang-Hsieh YF, Hou PF, Chang WC. EXPath: a database of comparative expression analysis inferring metabolic pathways for plants. BMC Genomics. 2015;16 Suppl 2:S6

\section{Submit your next manuscript to BioMed Central and we will help you at every step:}

- We accept pre-submission inquiries

- Our selector tool helps you to find the most relevant journal

- We provide round the clock customer support

- Convenient online submission

- Thorough peer review

- Inclusion in PubMed and all major indexing services

- Maximum visibility for your research

Submit your manuscript at www.biomedcentral.com/submit
Biomed Central 